\title{
Soft Computing Techniques and Applications in Electrical Drives Fuzzy logic, and Genetic Algorithm
}

\author{
${ }^{1}$ S. Sakunthala, ${ }^{2}$ R.Kiranmayi M.Tech, ${ }^{3}$ P.Nagaraju Mandadi \\ ${ }^{1}$ JNTUACEK - Kalikiri, JNTUA University, ${ }^{2}$ Ananthapur, JNTUA University, Ananthapur, ${ }^{3}$ SITAMS, \\ Chittoor, JNTUA University, Ananthapur \\ Email: shakuntala.btech@gmail.com, kiranmayi0109@gmail.com, mandadi.nagaraju@gmail.com
}

Received: $10^{\text {th }}$ December 2017, Accepted: 8th February 2018, Published: 28th February 2018

\begin{abstract}
Present days' technology requires new innovations which are implemented by using soft computing methods. The particular schemes have brought industrial capabilities to new changes in applications. Controlling mode is a significant use of several industries to control the complicated structure specifications. Present day's soft computing schemes are growing with good performance. These soft techniques are using the combination of conventional techniques which is used for develop machinery for resolving current controller difficulties. Soft computing schemes yield a power to make determinations and research from the certain knowledge or expert's experience. This paper mainly focuses on soft computing and hard computing techniques and the comparison of these techniques when applying for electrical motor drives.
\end{abstract}

\section{Keywords}

Soft and Hard computing techniques, the Fuzzy controllers with PMSM, Genetic Algorithm(GA), PI/PID, PMSM.

\section{Introduction}

Hard computing schemes are conventional computing schemes set on fundamentals of definiteness, serenity, and rigidness. Present days complications which process with uncertain of knowledge and estimated performance cannot be managed by such systems. It is observed that these schemes can have capability to solve tangible complications. despite, affecting considerable condition of hard computing schemes is that it takes a lot of estimation time to deal with complications as real-life problems are developed to hold estimated and undetermined data. There are different analytical models presented for dealing pre-determined requirements of real-life complications. However, real scenario presents that the physical complications occur in a non-ideal environment. several concurrent complications do not contain hard computing schemes for precise solutions. Figure 1 gives the different categories of computational methods [1-3].

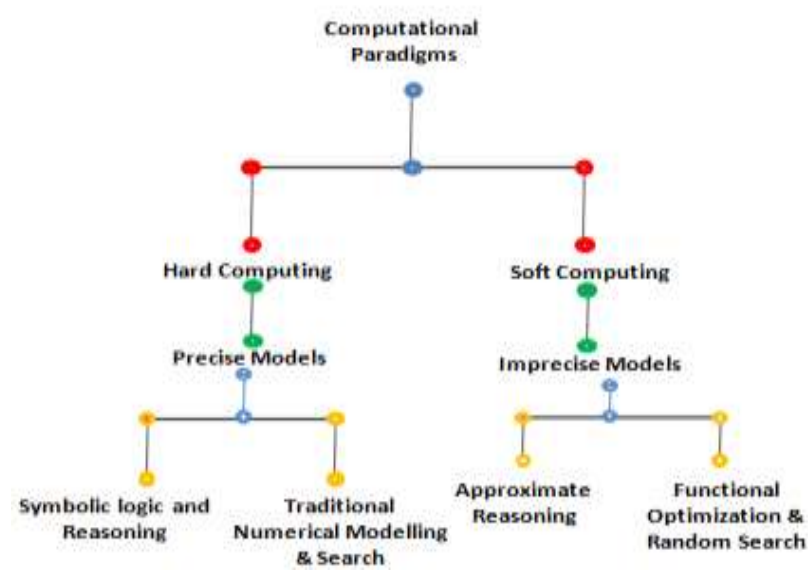

Figure 1: Categorization of computational methods

Intelligent System (IS) can be represented as the structure that integrates intelligence into utilizations being directed by electrical systems. To integrate intelligence into machine Utilizations, qualities such as interpretation, research, and adjustments are desired. Distinct from these aspects, search and optimization is another greater ability of IS. In order to understand with complicated real-world complications and to expose intelligence; an intelligent system desires a compound of knowledge, and schemes from many origins.. which deal with a defect, indefinite, low-cost solution, partial truth, and robustness can be developed by implementing soft computing techniques.

This technique is a developing selection of schemes, which aim to deed tolerance for the defect, indefinite, and partial truth to obtain power, conformity, and entire low cost. soft computing methods mimic recognition and acknowledge in various main considerations: they can learn from experience; they can generalize into fields where explicit observation is removed; and complete lateral computer designs to affect living mechanism, they can grow the mapping from inputs to the outputs faster than naturally serial systematic representations [3,4].

This technique is a crowd of computing methodologies that provide a support for the representation, design, and implementation of intelligent systems to provide economical and feasible solutions with reduced complexity. Figure 2 presents Different combinations of techniques from such ring have provided good results these techniques have their own strengths and limitations. Integration 
of three or more methods can provide important advantages for intelligent system design. for designing intelligent systems; e.g. soft computing methods.

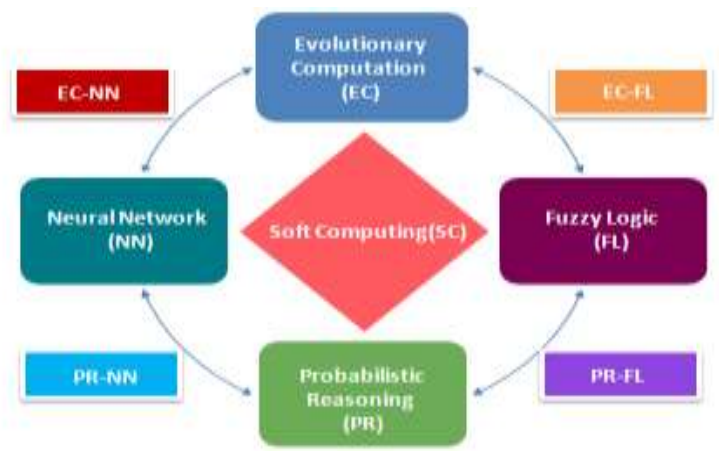

Figure 2: Principle division of soft computing system

Comparison of hard computing vs soft computing

In today's procreation, the type of computing can constitute a lot of variation in our daily essence and it can be classified into two types. They are one is hard computing and the second one is soft computing. Shown below table 1 is a simple comparison of two types of computing method that can help you to make your decision easier.

Table 1: Comparison of Hard Computing Vs Soft Computing

\begin{tabular}{|c|c|}
\hline Hard Computing & Soft Computing \\
\hline $\begin{array}{l}\text { Hard computing is } \\
\text { conventional computing, } \\
\text { desire a literally stated } \\
\text { systematic model and often } \\
\text { a moderately computation } \\
\text { time. }\end{array}$ & $\begin{array}{l}\text { It differs from standard } \\
\text { computing in that, dislike hard } \\
\text { computing, it is liberal of } \\
\text { imprecision, unreliability, } \\
\text { partial truth, an approximation. }\end{array}$ \\
\hline $\begin{array}{l}\text { It depends on zeros and } \\
\text { ones logic, crisp systems, } \\
\text { mathematical analysis and } \\
\text { crisp software }\end{array}$ & $\begin{array}{l}\text { Soft computing based on FLC, } \\
\text { neural nets, and probabilistic } \\
\text { reasoning. }\end{array}$ \\
\hline $\begin{array}{l}\text { It has the characteristics of } \\
\text { precision and categorist. } \\
\text { Although in it, imprecision } \\
\text { and variability are } \\
\text { unwanted properties, }\end{array}$ & $\begin{array}{l}\text { Soft computing, } \\
\text { approximation, in soft } \\
\text { dispensationalist. in and } \\
\text { computing, the liberality for } \\
\text { and unreliability is exploited to } \\
\text { obtain comfortability, lower } \\
\text { cost, high Machine Intelligence } \\
\text { Quotient (MIQ) and economy } \\
\text { of communication }\end{array}$ \\
\hline $\begin{array}{l}\text { It requires programs to be } \\
\text { written, uses two-valued } \\
\text { logic, is resolves, requires } \\
\text { real input data, is mainly } \\
\text { sequential, produces } \\
\text { valued answers }\end{array}$ & $\begin{array}{l}\text { It can derive its user own } \\
\text { programs, can use multivalued } \\
\text { or FLC, incorporates stochastic, } \\
\text { can process with differing and } \\
\text { noisy input, allows parallel } \\
\text { computations, can yield } \\
\text { approximate answers. }\end{array}$ \\
\hline
\end{tabular}

\section{Fuzzy Logic Controller}

Fuzzy logic controllers (FLC) are more powerful than PID controllers so they can utilize a much broad range of performing conditions than a PID can, and can produce with disturbances and noises of various nature. Developing a fuzzy controller is cheaper than developing a model-based controller or some other controller to carry out the same task. Fuzzy logic controllers are user designable since it is flexible to understand and customize their rules, it not only uses a user operator's scheme but is also expressed in natural linguistic terms. The fuzzy logic basic structure consists of four main components:
1. Fuzzy interface system
2. Knowledgebase
3. Selection-making logic
4. Defuzzification

Figure 3 presents the basic structure of FLC which consists of the fuzzy interface system, knowledge base, decision making logic and defuzzification [5-7].

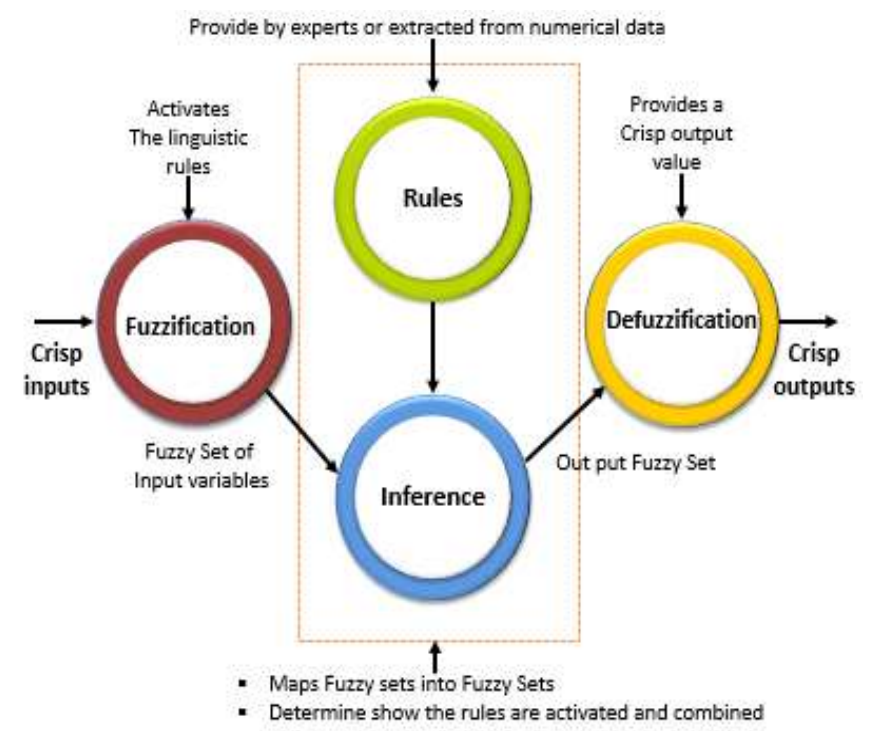

Figure 3: Basic Stature of Fuzzy Logic Controller

Procedure to design FLC:

Step 1. Determination of state variables and control variables.

Step 2. Determination of inference method

Step 3. Perseverance of fuzzification method

Step 4. Discretization normal of state variable space

Step 5. Partition of unsteady space

Step 6. Perseverance of the models of convoluted sets

Step 7. Arrangement of fuzzy rule base

Step 8. Determination of Defuzzification strategy

Step 9. Test and testing

Step 10. Construction of Lookup table

\section{Some areas of fuzzy logic applications:}

- Flexible manipulation of robots

- Camera- aiming for the telecast of sporting events

- Efficient and stable control of car engines

- Cruise -control for automobiles 
- Optimized designing of bus timetables

- System for early prediction of earthquakes

- Cancer diagnosis

- Motor control of vacuum cleaners automatically

- Light control for camcorders

Fuzzy controllers in consumer applications:

i. Consumer products

- Washing machines

- Microwave ovens

- Rice cookers

- Vacuum cleaners

- TVs and VCRs

- Thermal rugs

- Word translators

\section{ii. Systems}

- Elevators

- Trains

- Cranes

- Automotive

- Traffic control

iii. Software

- Medical diagnosis

- Securities

- Data compression

\section{FUZZY LOGIC CONTROLLER WITH PMSM}

The fuzzy controller(FLC) is used in PMS motor drives to estimate the errors of flux and torque and to reduce the ripples in torque due to that machine can work efficiently. In PMSM Drive fuzzy logic controller is used instead of PI (Proportional integral controller) [5-7]. while using PMSM the following points take place:

(1) fewer variables used for modeling than those needed to have a good model characterization of the system (learning with incomplete information);

(2) training data corrupted by noise;

(3) inverse modeling of the electrical drive system; and

(4) regions in the operating domain that have not received information during the training phase.Figure 4 presents the Block diagram of PMSM with a fuzzy logic controller.

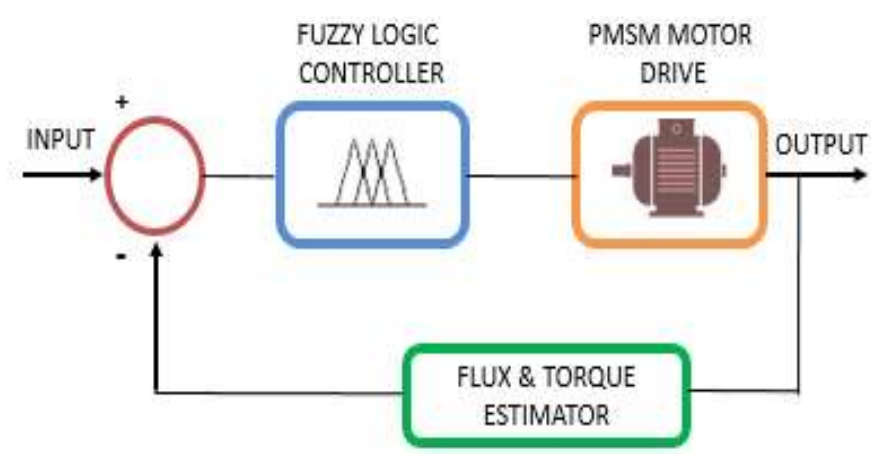

Figure 4: Principle Process structure of PMS Motor with Fuzzy Logic Controller

\section{Genetic Algorithm}

The genetic algorithm(GAs) desire to take two suitable unique and join them (this method of a approach called crossover). Offspring of the associated combination will get little different symptoms and nature of the father, and some of the mother. The GA controlling method is the of a process for expounding both driven and undriven optimization problems that depend on normal selection, the process that drives biological selection. The GA continuously revise a population of individual results. At each process of step, the GA chooses individuals at systematic from the present state to be parents and utilize them to grow the children for the future generation. Over-positive originations, the state "evolves" proceeding a normal solution. We can use the GA to solve a many types of optimization problems that are not suitable for normal optimization algorithms, including problems in which the objective method of the function is interrupted, nondifferentiable, problematic, or highly nonlinear [8]. The GA can identify problems of assorted integer GA programming, whether some elements are minimal to be integer-valued. The GA utilizes three main kinds of rules at each process of step to create the future generation of the present population:

- decision rules select the individuals, called parents, that participate in the population at the future generation.

- Crossover controls compound two parents to form children for the next generation.

- Mutation determine the behaviour to assign arbitrary changes to select sources to form children. 
Figure 5 gives the Basic process diagram of Genetic Algorithm

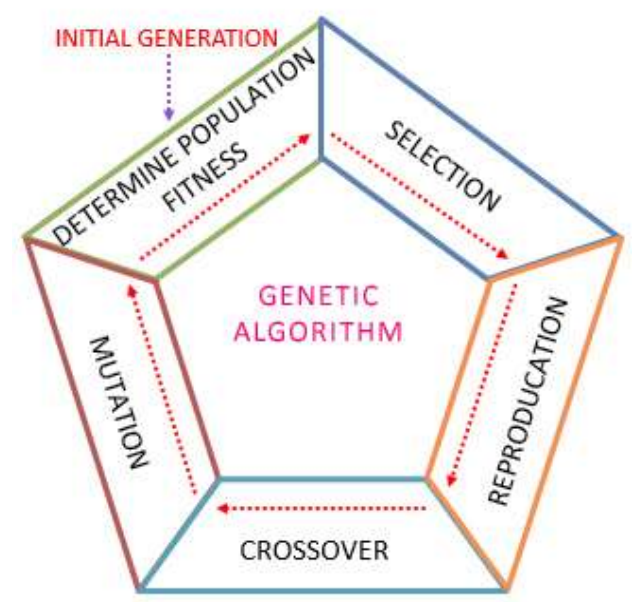

Figure 5: Basic Process of Genetic Algorithm

Steps followed in the genetic algorithm:

Step1: Random initialization of state

Step2: Evaluation of the fitness of particular in the state

Step3: New population generation

Step4: Evaluate population, GOTO step 2 end search for

Optimal solution, if stop criteria are reached

\section{GENETIC ALGORITHM APPLICATIONS:}

- Genetic Algorithms in Parametric Design of Aircraft

- $\quad$ Strategy Acquisition with GAs

- a GA approach to Multiple Error Diagnosis

- a GA for Conformational Analyzation of DNA

- A Hybrid Technique for Engineering Design Optimization

\section{Genetic Algorithm with PMSM}

GA is implemented in PMSM to reduce flux and torque ripples better than other controllers as shown in diagram number 6 . This algorithm is coded by using MATLAB software and fed to the PMSM instead of PID, PI and a fuzzy logic controller to perform the PMSM in a better way [8].

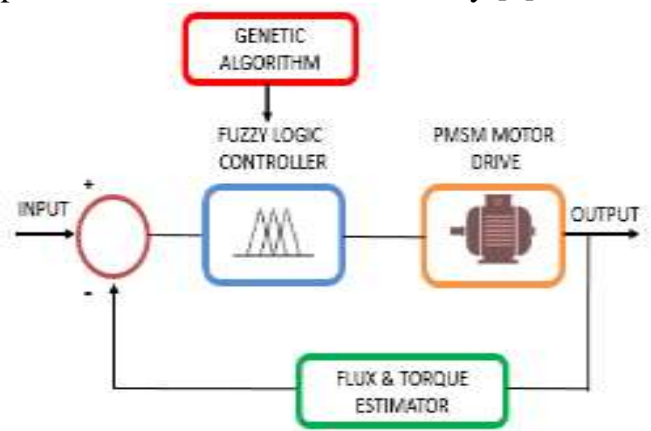

Figure 6: Basic Process Diagram of PMSM Genetic Algorithm

\section{Case Study On Direct Torque Control Of PMSM}

Artificial intelligence(AI) techniques are involved to overcome the drawbacks DTC approaches, such as starting problems from invalid cases, the control of flux measurement and torque. In a general method, voltage is applied for the total period, which successively yields high Is and EMT with a result high torque ripples are generate during motor action in an AI technique to resolve high potential decoupled $\psi$ and $\tau$ control have been performed in this work. Fuzzy logic implemented in an inverter state to get the $\tau$ and $\psi$ mentioned values [9-11]. For simulation, a $3 \phi, 2 \mathrm{KW}, 1500 \mathrm{rpm}$ PMSM motor drive is taken up. Mamdani model membership functions are used to represent the flux errors, EMT errors and flux angle. FLC rules is resolved by test and error method for the choosing of proper inverter state. A PMSM motor is subjected to a frequency of $50 \mathrm{~Hz}$, the specimen time of $5 \mathrm{~ms}$, and having torque and flux reference values of $1.5 \mathrm{Nm}$ and $0.8 \mathrm{~Wb}$ respectively [14]. For working conditions, $\mathrm{x}$ and $\mathrm{y}$ with hundred percent flux error of $2.7 \mathrm{e}-3$ and $3.6 \mathrm{e}-3$ are pointed for the FLC. Simulation analysis are implemented on various conducting states of the motor. It is hypothesized from the simulation outcomes that the development of flux error in fuzzy logic(FLC) and FL GA controllers are $23 \%, 22 \%, 19 \%, 18 \%$ and $17 \%$ for operating conditions $\mathrm{x}$ and $\mathrm{y}$ hundred percent Further, for operating conditions both $\mathrm{x}$ and $\mathrm{y}$ fifty percent performance improvement in flux errors range from $10 \%$ to $2 \%$ for fuzzy logic controllers. For the operating condition $\mathrm{a}$ and $\mathrm{b}$ with hundred percent the work development of about $5 \%$ is noted in fuzzy logic controllers. For many operating states the performance improvement is noted [9-13].

\section{Conclusion}

This paper consists various techniques of soft computing like the fuzzy logic controller and genetic algorithm. This soft computing technique is compared with hard computing techniques. The fuzzy logic controller (FLC) is implemented in PMSM instead of PI controller. By implementing this fuzzy controller, we can estimate the errors of flux and torque in PMSM. Errors can be minimized and compared by using the fuzzy logic(FLC) and the torque ripples in PMSM is reduced. In soft computing techniques, a genetic algorithm is also studied. How to implement this algorithm along with fuzzy controller in PMSM drives. The genetic algorithm can optimize the problems more easily than a Fuzzy controller and the advantages and applications of soft computing techniques are studied.by using this controller we can reduce the flux ripples and torque in the machine than conventional controllers.

\section{Acknowledgment}

I am very happy to be a part of the electrical world as a researcher. And I wish to thank all authors who supported me to write this paper. The paper, 
participating in its early stage and giving the idea to extend it up to a review paper. I would also like to thank the colleagues and friends for their fruitful cooperation, contribution, and discussions. My special thanks to my husband for complete support to do this paper.

\section{References}

1. Edelman, G.M., Neural Darwinism, Newyork: Basic Books, 1987.

2. Goldberg, D.E., Genetic Algorithms in search, optimization, and machine learning. Reading, M.A: Addison Wesley, 1989.

3. Holland, J.H 'Genetic Algorithm', Scientific American, pp.66-72, July 1992.

4. Vas, Peter, Artificial Intelligence-based electrical machines, and drives. Oxford University Press, 1999.

5. Lee, Kwang, H, The first course on fuzzy theory and applications. Springer international Edition, 2005.

6. Reznik, Leonid, Fuzzy controllers ewens, 1997.

7. "Neural Networks, Fuzzy Logic, And Genetic Algorithms: Synthesis And Applications" by S.Rajasekaran, G.A.Vijayalakshmi Pai. Published with "PHI Learning Private Limited" in 2013

8. "Introduction to Neural Networks, Fuzzy Logic \& Genetic Algorithms" by Sudarshan K.Valluru, T.Nageswara Rao. Published with "Jaico Publishing House" in 2010.

9. P. Pillay and R. Krishnan, "Modeling, analysis, and simulation of a high performance, vector controlled permanent magnet synchronous motordrive, in" Proc. IEEEIASAnn.Mtg., 1987.

10. R. Krishnan and P. Pillay, "Parameter sensitivity in a vector controlled ac motor drives," in Proc. 1987 IEEE IECON.

11. Krause P. "Analysis of Electric Machinery", New York, McGraw-Hill, 1986.

12. B. K. Bose, Power Electronics and AC drives, Prentice Hall, Englewood Cliffs, New Jersey, 1986.

13. R. Krishnan, "Selection criteria for servo motor drives," in Proc.IEEE IAS Ann.Mtg., 1986, pp. 301-308

14. R. Krishnan and A. J. Beutler, "Performance and design of an axial field Permanent magnet synchronous motor servo drive," in Proc. 